\title{
Urgences
}

\section{Roseline Grand-Maison et Michel Caillouette, Le Père Noël a-t-il oublié le Bas du Fleuve?, Sherbrooke, Naaman, 1983.}

\section{Bernard Boucher}

Numéro 8, 4e trimestre 1983

Littérature jeunesse

URI : https://id.erudit.org/iderudit/025128ar

DOI : https://doi.org/10.7202/025128ar

Aller au sommaire du numéro

\section{Éditeur(s)}

Urgences

\section{ISSN}

0226-9554 (imprimé)

1927-3924 (numérique)

Découvrir la revue

Citer ce compte rendu

Boucher, B. (1983). Compte rendu de [Roseline Grand-Maison et Michel

Caillouette, Le Père Noël a-t-il oublié le Bas du Fleuve? , Sherbrooke, Naaman,

1983.] Urgences, (8), 122-124. https://doi.org/10.7202/025128ar d'utilisation que vous pouvez consulter en ligne.

https://apropos.erudit.org/fr/usagers/politique-dutilisation/ 
Si les valeurs que véhicule ce livre le rejoignent, si la description ne l'écarte pas de la narration, si son goût du mouvement ou de l'aventure et si ses inquiétudes devant la vie trouvent leur compte, I'enfant s'attachera à Pinipère devenu source de piasir.

Bravo à son auteur. Bonne lecture aux grands et aux petits.

Lucie Gauvin, Département des sciences de I'Education, UQAR

$* * * * *$

LE PĖRE NOËL A-T-IL OUBLIÉ LE BAS DU FLEUVE?, Roseline Grand-Maison et Michel Caillouette, Naaman, 1983.

Pour faire un commentaire critique sur un conte pour enfants, doit-on tenter de se placer dans la perspective du lecteur ciblé ou jeter un regard d'adulte sur une écriture d'adulte destinée aux enfants? Selon I'optique choisie la nature du jugement peut s'en trouver profondément modifiée.

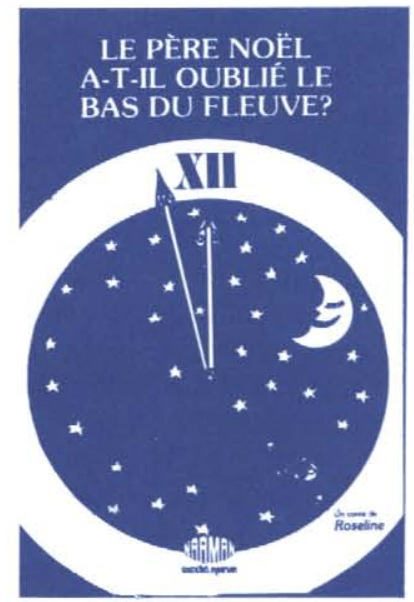

Comme on I'a déjà signalé dans les pages d'URGENCES, il faut avoir écrit (ou essayé de le faire) pour (ce qui diffère de par et 
avec) les enfants pour être en mesure de comprendre à quel point le subterfuge est énorme de croire qu'il est possible d'être un enfant le temps d'une écriture ou d'une lecture.

Roseline Grand-Maison publie aux Editions Naaman, dans la collection Jeunesse, un second conte intitulé LE PĖRE NOËL AT-IL OUBLIÉ LE BAS DU FLEUVE? Par suite de la lecture que j'en ai faite, il m'est apparu nécessaire de situer l'optique que l'on peut avoir de ce genre de travail. J'en retiens qu'une adulte a décidé d'offrir pour son plaisir, et celui recherché des apprentis lecteurs, une historiette toute simple sans intention pédagogique apparente, que les enfants pourront lire en guise de divertissement comme nous le faisons avec certains romans dont le parti pris est de nous raconter une histoire point.

Cela donne un conte d'une écriture qui, bien que soutenue, est parfois lourde, l'emploi d'un vocabulaire approprié, une imagerie que je qualifierais de neutre, sans recherche de figures de style, de mots, de sens, d'imagination ou de passions particulières. Du travail honnête.

La technique de l'illustrateur s'apparente à celle de l'auteure. Dans les deux cas l'intention de "faire enfant" semble les conduire à une approche naïvement naïve, veut-on nous laisser comprendre que c'est pareil comme si l'enfant l'avait fait luimême?

Les mauvaises notes vont malheureusement à l'édition; le format ne présente aucun attrait véritable pour ce genre de conte, les couleurs sont prises directement dans le tube, sans nuance, au moins cinq des trente et une pages sont réservées à des informations techniques (sans compter la couverture), la mise en page entraîne l'impression du texte en noir sur un ciel étoilé bleu primaire, et en prime nous avons un rappel du titre au bas de chacune des pages comme si on avait craint que nous ne l'oublions en cours de route.

Le conte intéressera les enfants. Pour éviter de vous livrer mes seules impressions (d'adulte) je les ai confrontées à celles de deux enfants. Leurs commentaires sont favorables mais sans 
éclats. À noter que le titre ne semble opérer aucune magie ni se révéler particulièrement efficace.

"Un conte de Roseline" qui fait partie de la littérature que les gens lisent en autobus, en train ou en avion; les enfants le liront en trottinette, à bicyclette ou en traîneau.

Bernard Boucher 